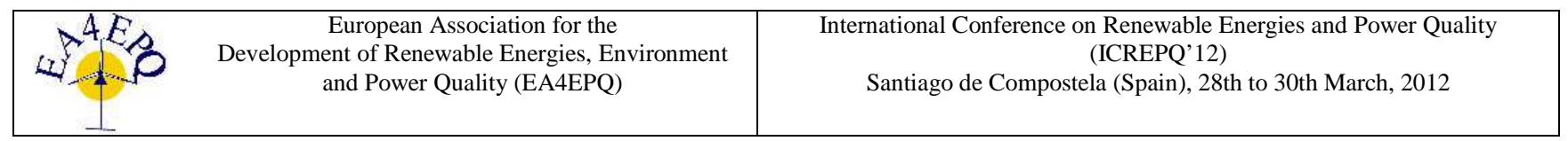

\title{
Computational Simulation versus Scale Model to determine the Optimal Shape of Tension Structures for the use of Sunlight in Road Tunnels
}

\author{
L.M. Gil-Martín ${ }^{1}$, A. Peña-García ${ }^{2}$, R. Escribano ${ }^{3}$ and A. Espín-Estrella ${ }^{2}$ \\ ${ }^{1}$ Department of Structural Mechanics. \\ ETSICCP, University of Granada. \\ Campus Fuentenueva - 18071 Granada (Spain) \\ Phone number: +34 958249 962, e-mail: mlgil@ugr.es \\ ${ }^{2}$ Department of Civil Engineering. \\ ETSICCP, University of Granada. \\ Campus Fuentenueva - 18071 Granada (Spain) \\ Phone number: +34 958249 435, e-mail: pgarcia@ugr.es, aespin@ugr.es \\ ${ }^{3}$ Department of Graphical Expression in Architecture and Engineering. \\ ETSIE, University of Granada. \\ Campus Fuentenueva - 18071 Granada (Spain) \\ Phone number: +34 958243 115, e-mail: rogaes@ugr.es
}

\begin{abstract}
Placement of semi-transparent tension structures in the portal gate of road tunnels to shift their threshold zone and use sunlight, has been proved to be an interesting procedure to save electrical energy. However, in order to obtain the maximum performance, the shape of the structure has to be established for each tunnel, depending on its geographic location, orientation and surroundings. In previous works, computational methods and a scale model have been used to determine the optimal shape of these structures without expensive and time costing trials. In this work, comparison of the results is presented and it shows that the virtual modeling combined with the previously derived ESTS equation can be used to choose of the most convenient structure.
\end{abstract}

\section{Key words}

Road tunnel, Lighting, Tension structures, Energy savings, Graphical design.

\section{Introduction}

It is known that the eye adaptation from bright to dark environments needs a quite long period of time that may take a minimum of eight minutes. Figure 1 represents the dark adaptation curve as a function of the time in dark.

This period of dark adaptation is unfeasible in driving, where one single second of delay or inaccurate visual performance implies a huge risk for the safety of the drivers. For this reason road tunnels need a more powerful lighting during daytime so that the driver eye does not lose any performance when going into them.
Regarding lightning, road tunnels are divided into several zones depending on the road and walls luminance supplied by the electrical lighting needed for a safe driving according to CIE Publ. 88, 2004 [2]. The luminance in the threshold zone (that is extended from the portal towards the interior of the tunnel), $\mathrm{L}_{\mathrm{th}}$, is the most important parameter in the lighting of tunnel in order to allow the drivers adaptation from the very bright environment to the relative darkness inside the tunnel.

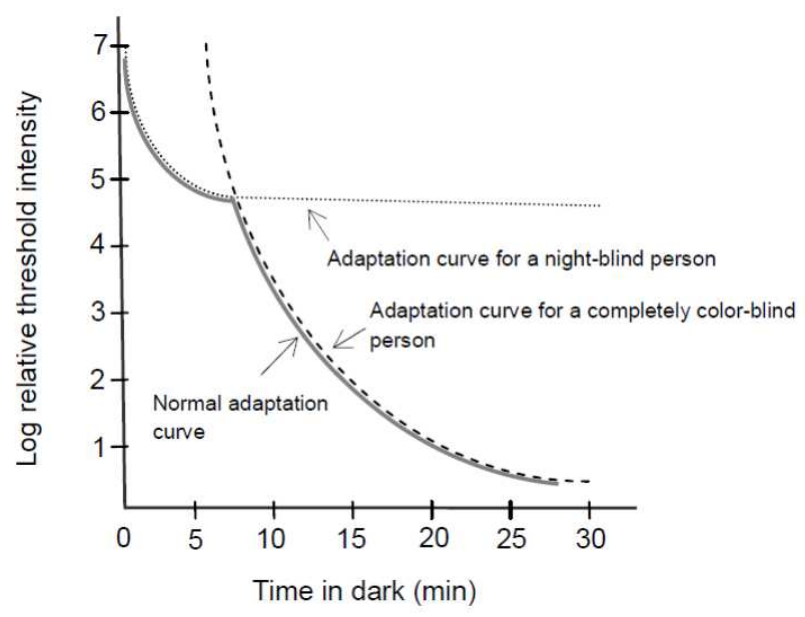

Fig. 1. Adaptation curve from bright to dark environments. Adapted from [1]. 
In this zone the required luminance is the highest in the whole tunnel, so any way to achieve $\mathrm{L}_{\text {th }}$ in this zone by reducing electrical lighting will mean an important energy saving, especially if we consider that lighting in tunnels operates continuously. In previous works $[3,4]$ it has been proved that the shift of the threshold zone out of the tunnel by means of semi-transparent tension structures allows using the sunlight in order to achieve the required levels of illuminance for this zone. This yields very remarkable energy savings.

The amount of luminous flux which can be profited to light the threshold zone depends on the location, orientation and surroundings of the road tunnel. Furthermore, there are other parameters of the tension structure, like their shape and material that might have influence on the obtained energy savings. Nevertheless, the optimal shape for each case is difficult to obtain because solutions that maximize the energy savings in the threshold zone will strongly depend on the orientation and location of the road tunnel. For this reason, it is necessary to find accurate tools in order to determine such optimal shape with minimum costs in time, money and media.

In [5] an expression which allows comparing any set of different tension structures in terms of energy savings, the ESTS equation (Energy Saving under Tension Structures), was presented. It is expressed as:

$$
\frac{Q_{t-S}}{Q_{t}}=1-S \frac{l_{S}}{l_{t}}
$$

Where

$Q_{t-S}$ is the energy consumed by the electrical lighting in the threshold zone when shifted by a tension structure,

$Q_{t}$ is the electrical energy consumed by the electrical lighting in the same threshold zone without a tension structure,

$S$ is the average energy savings under each tension structure, that is, the ratio between the mean illuminance on the road under the tension structure and the theoretical illuminance in the threshold zone. These values can be determined with measures of illuminance under real or scale tension structures or with a computing simulation,

$l_{S}$ is the length of the tension structure, and

$l_{t}$ is the length of the threshold zone.

In order to choose the most appropriate shape, a scale model of the real tunnel, sun, ecliptic and tension structure was used in [5]. However, because this procedure costs materials and time, a most economical method has also been investigated. So, free software commonly used in graphic design and cartoon movies has been used [6] to virtually simulate the insolation conditions of one specific tunnel in the most critical hours of the day, model different tension structures with different coatings and finally get the input for the ESTS equation, $S$.

The virtual models to evaluate the lighting environment have become an universal design tool for architects and daylighting researchers $[7,8]$. These daylighting simulation programs have been validated and their use is widespread $[9,10]$. Some of these lighting simulation tools [11] take as input a description of the geometry of the space and the optical characteristics of all surfaces and light sources, and their output is either illuminance or luminance distributions on or from the surfaces under consideration.

\section{Materials and methods}

A mock-up (scale 1:25) which simulated a long road tunnel with a mechanism that enabled it to adopt all possible orientations in a circle of $360^{\circ}$ has been built (see Figure 2). Above the mock-up, a sun ecliptic model was installed with an "Ultra Vitalux" $300 \mathrm{~W}$ lamp, which had the same spectral composition as sunlight. By changing the sun's position in relation to the tunnel, it is possible to simulate any tunnel location and orientation. In addition, the light source was able to slide along the ecliptic plane and thus simulate any hour of the day.

This simulation of a real tunnel allowed us to determine the most energy-efficient semi-transparent tension structure. For this purpose, three structures were tested. The shapes and dimensions of these tension structures were strongly conditioned by the space available at the entrance of the tunnel and the safety distances established in [2] (Figure 3).

In regards to energy efficiency, the optimal place for the anchoring points has to be determined for each tunnel, depending on its location and orientation. Once these anchoring points were defined, a final optimization was performed in order to obtain the simplest pattern design, and thus the most cost-efficient structure. The three structures studied in this research were designed so that the equilibrium shapes had sufficient slope to ensure that there would be no accumulation of material and to facilitate the elimination of rainwater drag. This meant that only low maintenance was necessary.

All the structures tested in laboratory were of polyester with a vanilla-colored PVC coating because of its relatively lower cost $\left(70 €-100 €\right.$ per $\mathrm{m}^{2}$ less than PTFE coating) and also because of the good transmittance values obtained for it in laboratory tests [4].

The illuminance under the tension structure was measured at six-centimetre intervals with a HT172 digital luxmeter. We decided to simulate June $21^{\text {st }}$, the most unfavourable day of the year because of the perpendicularity of solar rays at the location of the simulated tunnel $\left(37.11^{\circ} \mathrm{N}, 3.35^{\circ} \mathrm{W}\right.$ and $683 \mathrm{~m}$ above sea level in Pegálajar, Jaén, Spain). The insolation conditions were simulated at 12:00, 14:15, and 16:00.

Laboratory measurements considered direct sunlight as well as diffuse light or light from the rest of the sky. Diffuse light was taken into account by covering the tension structure with an opaque board and measuring the 
illuminance underneath the structure. Both components were added.

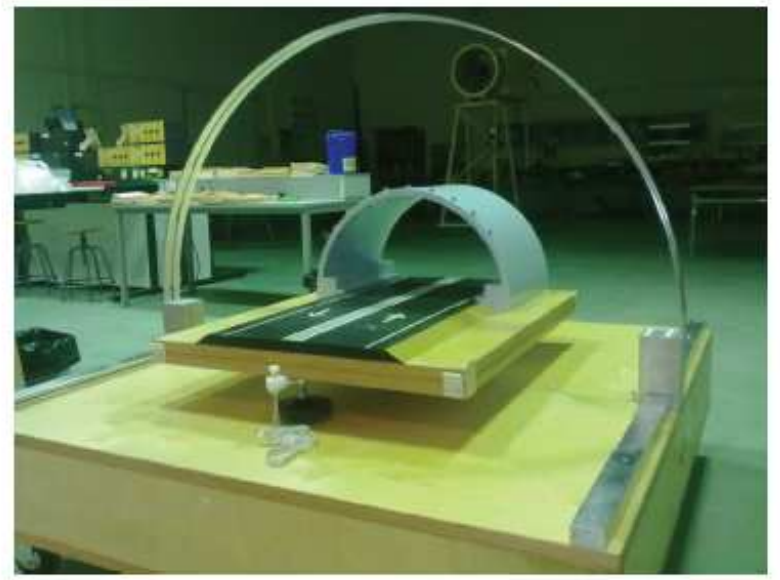

Fig. 2. Mock-up of the tunnel and solar ecliptic plane the insolation conditions of the tunnel in a quick and cheap way.

The virtually modeled tunnel, for which the candidate tension structures have been modeled, was the same previously studied using the mock-up. Figure 4.

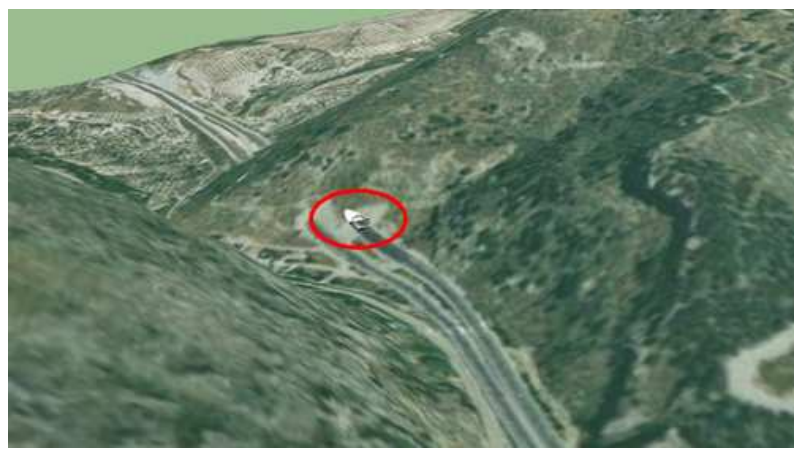

Fig. 4. Surroundings and location of the road tunnel and the tension structure.
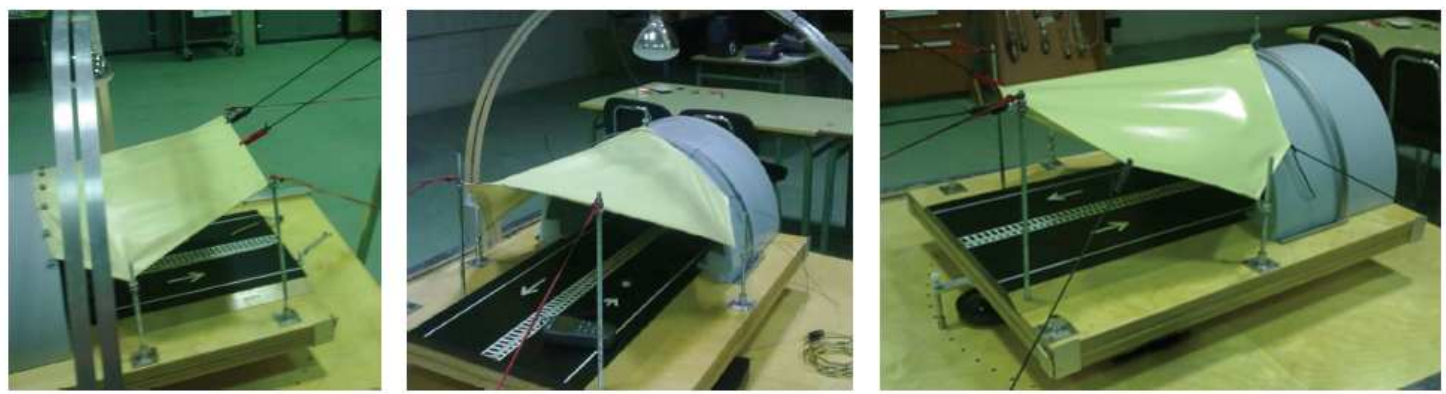

Fig. 3. Different tension structures placed in front of the portal gate of the tunnel.

Illuminance values obtained from the mock-up were corrected to be extrapolated to actual values introducing a correction factor arising from the radiation flux on the Earth's surface. Final results obtained from measures in the model using the ESTS equation are summarized in Table 1.

\begin{tabular}{||c|c||}
\hline & ENERGY SAVINGS (MWH) \\
\hline Structure 1 & 4.7 \\
\hline Structure 2 & 5.1 \\
\hline Structure 3 & 4.3 \\
\hline
\end{tabular}

Table 1. Energy savings (MWh) per year in the threshold zone for the three tension structures tested.

As alternative to the modeling of tension structures using a mock-up, thus saving time and money, the modeling has been carried out also with free software, Blender, which can be defined as a free open source 3D content creation suite (http://www.blender.org). To introduce the light effect, the program LuxRender, also free, has been used (http://www.luxrender.net). This tool simulates the flow of light according to physical equations, which makes the results highly reliable. In the context of this work, this software allows the accurate simulation of any shape of tension structure, built with different fabrics and whatever
The characteristics of the modeled atmosphere and sun used in the model of Render have been summarized in Table 2.

\begin{tabular}{|c|c||}
\hline $\begin{array}{c}\text { Sky } \\
\text { component }\end{array}$ & $\begin{array}{c}\text { Turbidity: default clear sky value 2,2 } \\
(2-50)\end{array}$ \\
\hline $\begin{array}{c}\text { Sun } \\
\text { component }\end{array}$ & $\begin{array}{c}\text { Turbidity: default clear sky value 2,2 } \\
(2-50)\end{array}$ \\
\hline $\begin{array}{c}\text { World } \\
\text { medium }\end{array}$ & $\begin{array}{c}\text { Air @ STP } \\
\text { (preset based in index of refraction of air) }\end{array}$ \\
\hline Location & Lat: $37.11^{\circ} ;$ Long: $3.35^{\circ}$ \\
\hline Date & June $21^{\text {st }}$ \\
\hline
\end{tabular}

Table 2. Input parameters for the virtual modeling.

The shape of the tension structure has been introduced in the model by a list of nodes that define its equilibrium position. The shape of the structure or equilibrium position has been obtained using topological mapping $[12,13]$. The advantage of this kind of mapping is that an initial guess of the tension structure equilibrium position is not needed. In contrast to the mapping methods based exclusively on geometry, only the coordinates of the fixed nodes of the structure need to be defined to obtain the final shape of the structure. To generate the network 
that defines the shape of the structure software developed at the University of Granada has been used.

The mapping of these structures, that defines their equilibrium shapes, is represented in Figure 5.

Although the base material of the structures under study is polyester, three different coatings with different optical properties have been simulated for each shape. This will allow us to decide which couple polyester-coating yields higher energy savings. In order to avoid handling with long and thorny commercial references, the different couples polyester-coating will be labeled as material 1 , material 2 and material 3.

From virtual simulation, the energy savings per year for each tension structures has been obtained. Table 3 summarizes these energy savings (MWh) for a mean period of 8 hours of sun per day (the usual period in Spain). length or shape. Otherwise, extremely expensive and time consuming trials in real tunnels would be necessary.

Calibrated models with Blender allow the engineer to decide the tension structure and material more suitable for use in each road tunnel in a very quick and cheap way. These simulations, together with the ESTS equation [5] get the optimal tension structure set in front of the entrance of the road tunnel in order to use the sunlight and save energy from the electrical lighting during daytime.

\section{Acknowledgement}

This research work was carried out under the financial support provided by Spanish Ministry of Education and Science as part of the Research Project BIA 2007-62595.
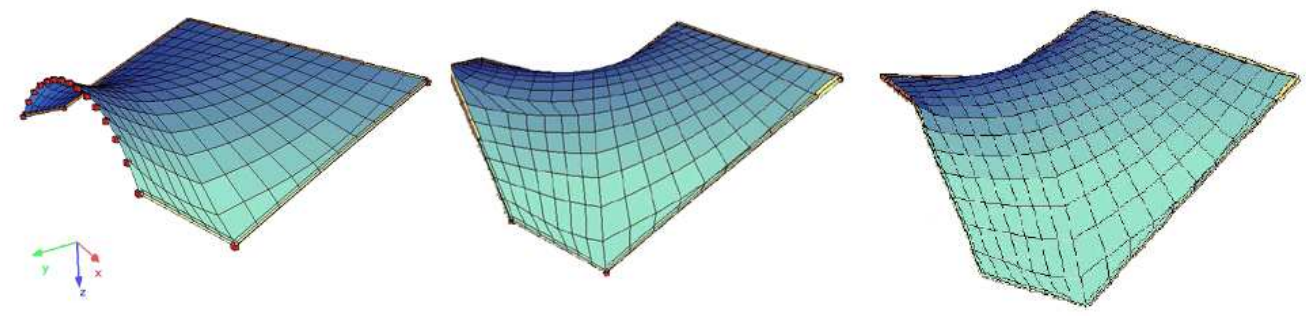

Fig. 5. Equilibrium shapes of the modeled structures.

\begin{tabular}{||c|c|c|c||}
\hline $\begin{array}{c}\text { Tension } \\
\text { structure }\end{array}$ & $\begin{array}{c}\text { Energy savings for } \\
\text { Material 1 (MWh) }\end{array}$ & $\begin{array}{c}\text { Energy savings for } \\
\text { Material 2 (MWh) }\end{array}$ & $\begin{array}{c}\text { Energy savings for } \\
\text { Material 3 (MWh) }\end{array}$ \\
\hline Structure 1 & 4,5 & 5,2 & 5,2 \\
\hline Structure 2 & 4,9 & 5,6 & 5,5 \\
\hline Structure 3 & 4,5 & 5,4 & 5,4 \\
\hline
\end{tabular}

Table 3. Global energy savings (MWh) in the threshold zone for the three tension structures with three different coating materials.

In all the mock-ups tested in laboratory, tension structures were built using Material 1. Comparison of Tables 1 and 3 shows that the estimation of savings from both, virtual modeling and mock-ups, are quite similar.

\section{Conclusions}

Both scale models and computational methods using free software Blender, have proved to be effective tools to quantify the energy savings achieved in road tunnels by means of semi-transparent tension structures. However, the computational method is quicker and very cheap and allows us to decide which tension structure and which material is the most suitable for each specific road tunnel among a large set of candidates whatever their material,

\section{References}

[1] Schmidt, R.F., 1978. Fundamentals of Sensory Physiology, Springer-Verlag, NY.

[2] Commission Internationale de l'Éclairage, CIE, 2004. Guide for the lighting of road tunnels and underpasses, CIE Publ. 8 , Vienna.

[3] Peña-García, A., Gil-Martín, L.M., Espín-Estrella, A., Aznar-Dols, F., 2010. Energy saving in road tunnels by means of transparent tension structures. International Conference on Renewable Energies and Power Quality (ICREPQ'10). Granada (Spain). ISBN: 978-84-613-7543-1.

[4] Gil-Martín, L.M., Peña-García, A., Hernández-Montes, E., Espín Estrella, A., 2011. Tension structures: A way towards sustainable lighting in road tunnels. Tunnelling and Underground Space Technology. 26, 223-227. 
[5] Peña-García, A., Gil-Martín, L.M., Escribano R. EspínEstrella, A., 2011. A Scale Model of Tension Structures in Road Tunnels to Optimize the Use of Solar Light for Energy Saving. International Journal of Photoenergy. 2011, 9pp.

[6] Gil-Martín, L.M., Peña-García, A., Escribano, R., EspínEstrella, A., 2011. A computational method to optimize energy savings of tension structures set in road tunnels. In Proceedings of International Conference on Renewable Energies and Power Quality (ICREPQ'11). Las Palmas de Gran Canaria (Spain).

[7] Scartezzini, J.L, Compagnon, R., Ward, G, Paule, B., 1994. Computer Daylighting Simulation Tools. Technical Report. University of Geneva/EPFL, Lausanne, Switzerland.

[8] International Energy Agency, 1999. Survey Simple Design Tools, Report of IEA SHC Task 21 /ECBCS Annex 29. Stuttgart.

[9] Love, J.A., Navvab, M., 1991. Daylighting estimation under real skies: a comparison of full-scale photometry and computer simulation. Illuminating Engineering Society 20, 140-156.

[10] Maamari, F., Fontoynont, M., 2003. Analytical tests for investigating the accuracy of lighting programs. Lighting Res. Technol. 35, 225-242.

[11] Ward Larson, G., Shakespeare, R.A., 1998. Rendering with Radiance. The Art and Science of Lighting Visualization. Morgan Kaufmann Publishers.

[12] Hernández-Montes, E., Jurado-Piña, R., Bayo, E., 2006. Topological mapping for tension structures. J. Struct. Eng. ASCE. 132, 970-977.

[13] Jurado-Piña, R., Gil-Martín, L.M., Hernández-Montes, E., 2009. Topological mesh for shell structures. Applied Mathematical Modelling. 33, 948-958. 